\title{
SCIENTIFIC REPORTS

\section{Symmetrical electrophysiological brain responses to unilateral and bilateral auditory stimuli suggest disrupted spatial processing in schizophrenia}

\begin{abstract}
Sara Sardari ${ }^{1}$, Ali Mohammad Pourrahimi ${ }^{1}$, Hossein Talebi ${ }^{3}$ \& Shahrzad Mazhari ${ }^{1,2 *}$
Research has found auditory spatial processing deficits in patients with schizophrenia (SCZ), but no study has examined SCZ patients' auditory spatial processing at both pre-attentional and attentional stages. To address this gap, we investigated schizophrenics' brain responses to sounds originating from different locations (right, left, and bilateral sources). The event-related potentials (ERPs) of 25 chronic schizophrenic patients and 25 healthy subjects were compared. Mismatch negativity (MMN) in response to frequency and duration deviants was assessed. Two $\mathrm{P} 3$ components ( $\mathrm{P} 3 \mathrm{a}$ and $\mathrm{P} 3 \mathrm{~b}$ ) were elicited via a frequency discrimination task, and $M M N$ and $P 3$ were recorded through separate monaural and dichotic stimulation paradigms. Our results corroborated the previously published finding that MMN, P3a, and P3b amplitudes are reduced in SCZ patients, but they showed no significant effect of stimulus location on either MMN or P3. These results indicated similarity between the SCZ patients and healthy individuals as regards patterns of ERP responses to stimuli that come from different directions. No evidence of auditory hemispatial bias in the SCZ patients was found, supporting the existence of non-lateralized spatial processing deficits in such patients and suggesting compensatory changes in the hemispheric laterality of patients' brains.
\end{abstract}

The processing of the spatial location of incoming stimuli is a crucial function of the brain as it enables spatial orientation and coherent perception of the world. Patients with schizophrenia (SCZ) experience a variety of daily life problems, many of which are rooted in spatial processing deficits ${ }^{1-5}$. Studies on spatial-visual processing in SCZ presented strong evidence of right- or left-side bias toward one side of the sensorium, which results in the failure to orient attention to stimuli from one side of space and the consequent loss of stimulus perception ${ }^{4,6-8}$. Hemispatial neglect is an extreme cause of spatial unawareness that is defined as the possibility of completely missing information from a given spatial region. Although this condition is usually observed in patients with right-brain lesions ${ }^{9}, \mathrm{SCZ}$ individuals have also been suggested to suffer from neglect-like disorders ${ }^{10}$. Recent research further showed that SCZ individuals may detect simultaneously the presented bilateral visual stimuli, but fail to recognize unilateral stimuli, which is another spatial processing disorder called anti-extinction ${ }^{11}$. As can be seen, abundant studies have been devoted to spatial attention and processing in relation to visual modality in SCZ, but little is known about unilateral and bilateral spatial processing in auditory modality. The auditory regions of the cerebral cortex are located in the superior temporal gyrus (STG), which contains the primary auditory cortex (Heschl's gyrus) ${ }^{12}$. Neuroimaging and post-mortem studies found that SCZ patients exhibit structural changes in auditory regions, particularly the $\mathrm{STG}^{13}$, and research on auditory event-related potentials (ERPs) provided strong evidence of cortical processing dysfunctions in SCZ subjects ${ }^{14,15}$. In one ERP investigation, for example, SCZ patients less accurately determined the location of a sound source than did healthy controls ${ }^{16}$.

Given the critical role of spatial processes in everyday living, the present work compared the auditory spatial functioning of SCZ patients and healthy individuals. The main goal was to ascertain whether brain-evoked

${ }^{1}$ Neuroscience Research center, Institute of Neuropharmacology, Kerman University of Medical Sciences, Kerman, Iran. ${ }^{2}$ Department of Psychiatry, Medical School, Kerman University of Medical Sciences, Kerman, Iran. ${ }^{3}$ Audiology department, Rehabilitation faculty, Isfahan University of Medical Sciences, Isfahan, Iran. *email: Smazhari@kmu.ac.ir 


\begin{tabular}{|l|l|l|}
\hline Variable & $\begin{array}{l}\text { Patients } \\
\mathbf{N = 2 5}\end{array}$ & $\begin{array}{l}\text { Controls } \\
\mathbf{N = 2 5}\end{array}$ \\
\hline Education & $11.0 \pm 3.0$ & $12.0 \pm 1.3$ \\
\hline Gender N (\% male) & $22(88 \%)$ & $22(88 \%)$ \\
\hline Edinburgh & $95.2(9.5)$ & $96.5(9.0)$ \\
\hline PANSS Positive & $14.0(4.1)$ & - \\
\hline PANSS Negative & $16.9(4.8)$ & - \\
\hline Length of the illness (year) & $13(8.6)$ & - \\
\hline $\begin{array}{l}\text { Chlorpromazine } \\
\text { equivalent dose (mg/day) }\end{array}$ & 457 & - \\
\hline
\end{tabular}

Table 1. Demographic and clinical characteristics of the participants (mean \pm SD). ${ }^{a}$ Chlorpromazine equivalent dose. Abbreviation: PANSS: positive and negative symptom scale.

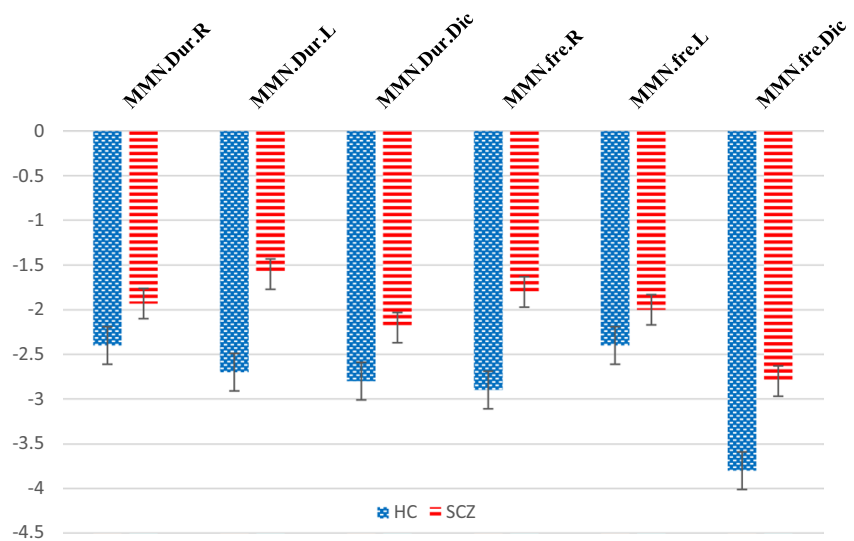

Figure 1. MMN amplitudes in patients (SCZ) and controls (HC).

potentials in response to right- and left-side sounds differ in terms of amplitude and latency within and between study groups. The study was also intended to determine dissimilarities between the groups with respect to ERPs evoked by bilateral sounds. To these ends, we implemented a set of ERP measures to obtain insights into spatial auditory processing in SCZ patients and assessed mismatch negativity (MMN) in response to both frequency and duration deviants. MMN responses reflect an automatic or pre-conscious process of detecting a mismatch between frequently and rarely encountered stimuli (e.g., difference in sound duration or pitch) ${ }^{17}$. Because of the subconscious nature of MMN, a logical approach was to examine higher-order cognitive processes-a requirement that we completed by evoking P3a (novelty P3) and P3b ERP components using separate tasks. P3a is elicited via task-irrelevant novel stimuli, whose saliency enable them to capture subject's attention, even though these triggers are unintentionally heeded ${ }^{18}$. The key difference between P3a and MMN, then, lies in the level of consciousness involved; that is, subtle differences between frequent and deviant stimuli are ignored under MMN, especially if an individual is distracted ${ }^{19}$. P3b is elicited by attended task-relevant stimuli and reflects the allocation of attentional resources when a target stimulus engages memory operations during task performance ${ }^{20}$.

\section{Results}

Subjects' characteristics. Table 1 shows the demographic and clinical characteristics of the participants. The healthy controls (HC) and the SCZ patients were matched in terms of age, gender, and educational level. The MMN and $\mathrm{P} 3$ amplitudes and latencies were subjected to repeated-measures ANOVA involving one betweengroup factor (HC, SCZ), two within-group factors of region ( $\mathrm{Fz}, \mathrm{Cz}$, and $\mathrm{Pz}$ electrodes), and stimulus location (left, right, dichotic).

Right versus left stimulus presentation. Figure 1 shows the frequency and duration MMN amplitudes in HC and SCZ groups. The duration and frequency MMN grand averages for each group are depicted in Fig. 2a,b, respectively. With regard to duration MMN, ANOVA showed that group composition exerted a significant main effect on amplitude $\left[F(1,38=4.6), p=0.02, \mathrm{n}^{2}=0.1\right]$ and latency $\left[F(1,38=4.1), p=0.04, \mathrm{n}^{2}=0.09\right]$ (Fig. 1). Follow-up comparisons showed that the SCZ patients exhibited significantly smaller amplitudes and shorter latencies for both right- and left-side stimuli $(p<0.05)$. Stimulus location had no main effect on amplitude or latency in all directions $(p>0.05)$. With respect to frequency MMN, grouping did not exert a significant main effect on amplitude $\left[F(1,36=3.6), p=0.06, \mathrm{n}^{2}=0.09\right]$ or latency $\left[F(1,36=2.8), p=0.1, \mathrm{n}^{2}=0.07\right]$. As with duration $M M N$, frequency MMN reflected no significant effect of stimulus location on amplitude or latency $(p>0.05)$. 
Left

a

$\mathrm{HC}$

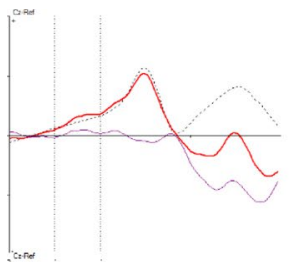

SCZ

b

c

HC

HC

SCZ
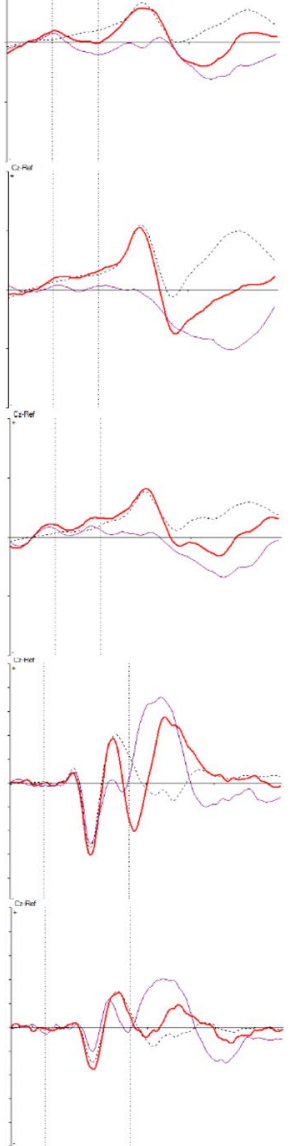

Bilateral

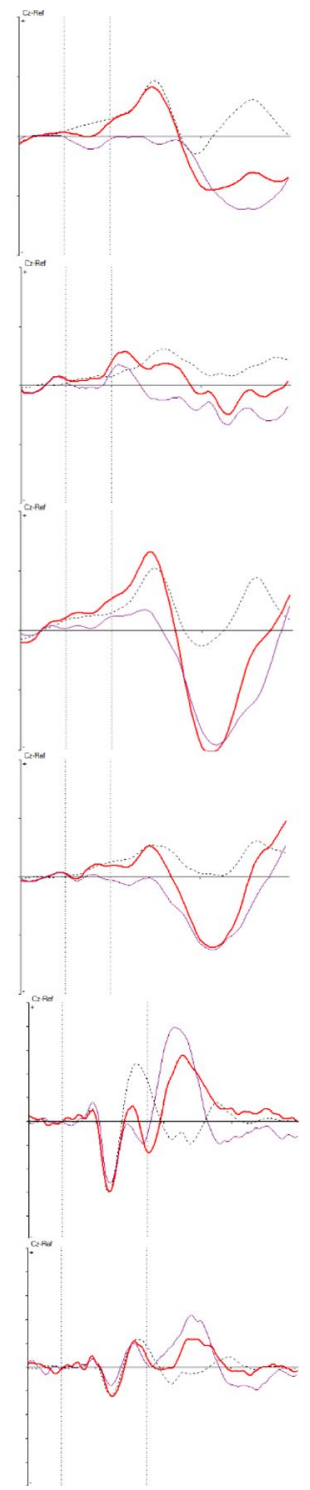

Right

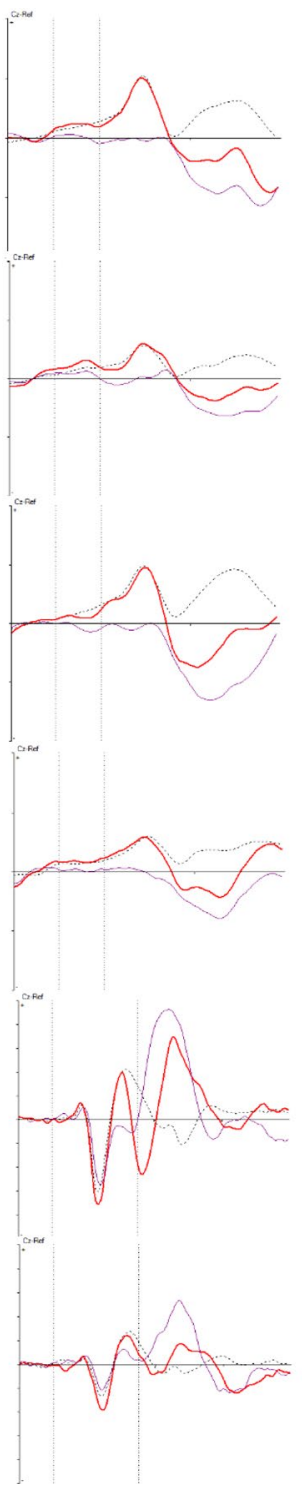

Standard

Deviant

Difference

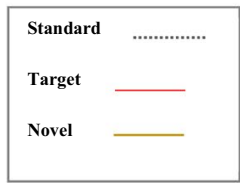

Figure 2. Grand average ERPs at $\mathrm{Cz}$ in response to stimuli origination from the left (left column), bilateral (central column), and right (right column) directions (HC: upper row, SCZ: lower row). (a) duration MMN, (b) frequency MMN, (c) P3a and P3b components.

P3a and P3b grand averages for each group are depicted in Fig. 2c. Figure 3 compares the P3a (left) and the P3b (right) amplitudes in the groups for unilateral and bilateral stimulation. The model indicated a significant effect of group composition on P3a amplitudes $\left[F(1,43)=24.7, p<0.001, \mathrm{n}^{2}=0.3\right]$. A follow-up analysis showed that the SCZ group had significantly smaller amplitudes for left- and right-originating stimuli $(p<0.001)$ but that stimulus location exerted no significant effect $\left[F(1,43)=1.2, p=0.2, \mathrm{n}^{2}=0.02\right]$. The model also showed that group composition caused a significant main effect on P3b amplitudes $\left[F(1,43)=23.7, p<0.001, \mathrm{n}^{2}=0.3\right]$. The SCZ patients had significantly smaller amplitudes for stimuli originating from both left and right $(p<0.001)$. Stimulus location did not cause any significant main effect on $\mathrm{P} 3 \mathrm{~b}$ amplitudes $\left[F(1,43)=1.5, p=0.2, \mathrm{n}^{2}=0.03\right]$. The group composition effects on P3a and P3b latencies were also nonsignificant $(p>0.05)$. Table 2 presents a detailed description of ERP amplitudes and latencies in HCs and SCZs.

Binaural versus unilateral stimulus presentation. Concerning duration MMN, the group composition exerted a significant main effect on amplitude $\left[F(1,38)=4.2, p=0.04, \mathrm{n}^{2}=0.1\right]$ and latency $[F(1,38)=6.9$, $\left.p=0.01, \mathrm{n}^{2}=0.1\right]$. This finding is attributed to the significantly smaller amplitudes and shorter latencies of the SCZ patients at all stimulus directions $(p<0.05)$. Stimulus location had a nonsignificant effect on amplitude and latency $(p<0.05)$. As to frequency MMN, the group composition exerted a significant main effect on amplitude $\left[F(1,36)=4.6, p=0.03, \mathrm{n}^{2}=0.1\right)$, and the SCZ patients had significantly smaller amplitudes than did the controls 


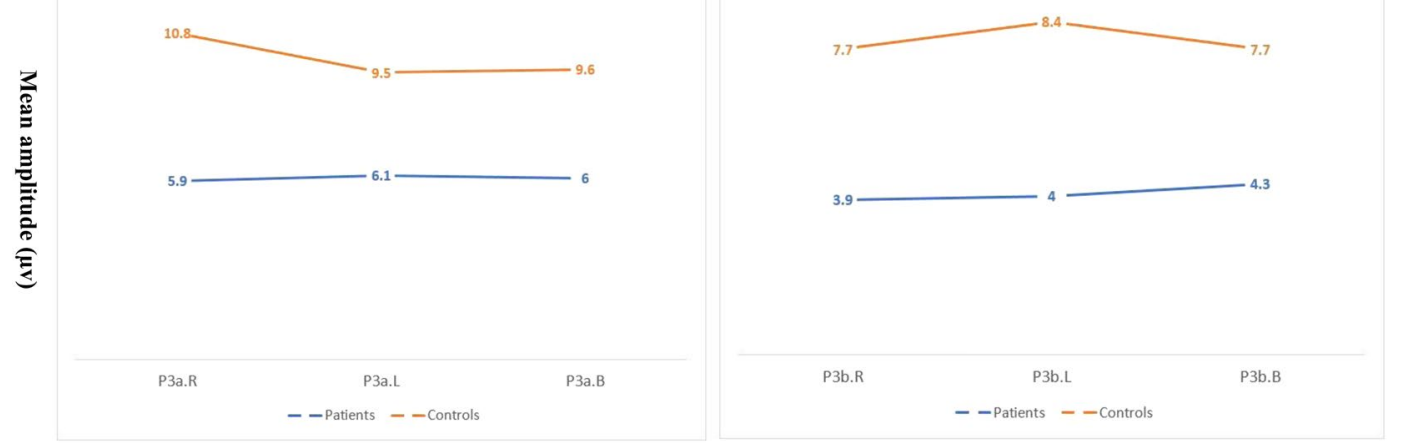

Figure 3. P3a (A) and P3b (B) amplitudes for right (R), left (L), and bilateral dichotic (dic) directions (SCZ vs. HC).

for all stimulus locations $(p<0.05)$. Stimulus location exerted a significant effect $[F(2,72)=20.0, p<0.001$, $\mathrm{n}^{2}=0.3$ ], indicating changes in amplitude at different stimulus directions. The interaction between stimulus direction and group composition was nonsignificant $\left[F(2,72)=1.2, p=0.2, \mathrm{n}^{2}=0.03\right]$, suggesting that the rates of amplitude variations were similar across the groups. The model indicated that group composition exerted no significant main effect on latency $\left[F(1,36)=2.6, p=0.1, \mathrm{n}^{2}=0.06\right]$ but that stimulus direction significantly affected amplitude $\left[F(2,72)=4.5, p=0.01, \mathrm{n}^{2}=0.1\right]$. These results are ascribed to the significantly shorter latencies among the SCZ patients than among the HCs for left and bilateral sources of stimuli $(p<0.05)$. The interaction between stimulus direction and grouping was nonsignificant $\left[F(2,72)=0.4, p=0.4, \mathrm{n}^{2}=0.01\right]$, implying that the patterns of amplitude variations were similar across the groups.

In connection with $\mathrm{P} 3 \mathrm{a}$, the statistical model showed a significant main effect of group composition on amplitudes $\left[F(1,42)=22.3, p<0.001, \mathrm{n}^{2}=0.3\right]$ and latencies $\left.[F(1,42)=6.0), p=0.01, \mathrm{n}^{2}=0.1\right]$. The P3a amplitudes were significantly smaller, and the latencies were significantly longer among the SCZ patients in all stimulus directions (all $p<0.05)$. Stimulus direction did not significantly influence amplitude $[F(2,84)=0.7, p<0.4$, $\left.\mathrm{n}^{2}=0.01\right]$ or latency $\left.[F(2,84)=0.7), p=0.4, \mathrm{n}^{2}=0.01\right]$, suggesting similarity in amplitude changes with directional variations. In relation to $\mathrm{P} 3 \mathrm{~b}$, the model showed a main effect of group composition on amplitudes $[F(1$, $\left.42)=23.7), p<0.001), \mathrm{n}^{2}=0.3\right]$ and latencies $\left.\left.[F(1,42)=6.5), p=0.01\right), \mathrm{n}^{2}=0.1\right]$. This finding is due to the significantly smaller P3b amplitudes and longer latencies among the SCZ patients for all stimulus locations $(p>0.5)$. Stimulus location did not significantly affect P3b amplitude or latency.

\section{Discussion}

This study investigated the ERPs evoked by unilateral and bilateral sounds at different attentional levels, namely, (1) subconscious attention to subtle differences in sensory inputs (MMN), (2) conscious but unwanted attention to attention-capturing stimuli (P3a), and (3) voluntary and goal-directed attention (P3b) in SCZ. Consistent with imaging ${ }^{21}$ and $\mathrm{ERP}^{22}$ studies, our results demonstrated overall reduced MMN, P3a, and P3b amplitudes in the SCZ patients, indicating that the trials were sensitive to the differentiation of the patients from the controls. However, the effects of stimulus location on the ERP amplitudes and latencies of the groups were comparable. We discuss this finding for the unilateral and bilateral stimulus presentations separately.

In case of right vs left side stimulation, the symmetric MMN responses to different locations of frequency or pitch deviance in the SCZ patients suggested a dysfunction in the automatic comparison of an existing memory trace with incoming novel stimuli, which were unaffected by stimulus direction. There are contradictory reports on the patterns of MMN responses to lateralized stimuli in SCZ. Our findings support those of previous studies in that they implied a symmetric volume loss or hypoactivation of the STG in SCZ ${ }^{21,23,24}$. As discussed in past research, because the STG is the main brain-related generator of MMN, its anomalies can result in the well-known MMN amplitude decrement in schizophrenic patients. Post-mortem studies on SCZ patients also showed neuronal loss in auditory-related areas of the anterior cingulate cortex (ACC $)^{25,26}$ and mid-dorsolateral prefrontal cortices ${ }^{27}$. With regard to robust anatomical links between ACC and the frontal auditory areas ${ }^{27}$, the descent of inputs from the latter to the former can induce a symmetric drop in ERP responses ${ }^{28,29}$, as was observed in the present work.

Similar to the MMN, the P3a and P3b components indicated that stimulus direction exerted comparable effects on the amplitudes and latencies of the two groups-a phenomenon that can be related to a general deficit in both hemispheres. These findings are consistent with some research that reported the bilateral hypoactivation of $\mathrm{P} 3$ a sources ${ }^{30-32}$ and $\mathrm{P} 3 \mathrm{~b}$ generators ${ }^{32-34}$.

When comparing unilateral vs bilateral stimulation, our results revealed comparable responses to binaural and unilateral auditory stimuli. The P3a and P3b deficits observed in the present work and similar studies uncovered that target and distractor processing involves distinct subsystems and that such processing types are altered in SCZ in a symmetrical pattern ${ }^{35}$. Consistent with our findings, imaging studies reported frontal lobe and cingulate hypofunction in SCZ; that is, the frontal lobe engages in discriminatory tasks, which is essential for P3 generation $^{36}$, whereas the cingulate gyrus is involved in the effortful initiation (P3b) and inhibition (P3a) of motor responses ${ }^{37}$. On a battery of psychological tasks, SCZ patients showed significant impairments in tests that were sensitive to right or left frontal and temporal lobe damage, but they performed normally in tests that were 


\begin{tabular}{|c|c|c|c|c|c|c|c|c|c|c|c|c|c|c|c|c|c|c|c|c|}
\hline \multirow{3}{*}{$\begin{array}{l}\text { ERP } \\
\text { component }\end{array}$} & \multirow{3}{*}{$\begin{array}{l}\text { Deviance } \\
\text { type }\end{array}$} & \multirow{3}{*}{\begin{tabular}{|l|}
$\begin{array}{l}\text { Direc } \\
\text { tion }\end{array}$ \\
Region \\
group \\
\end{tabular}} & \multicolumn{6}{|l|}{ Right } & \multicolumn{6}{|l|}{ Left } & \multicolumn{6}{|l|}{ Both } \\
\hline & & & \multicolumn{2}{|l|}{$\mathrm{Fz}$} & \multicolumn{2}{|l|}{$\mathrm{Cz}$} & \multicolumn{2}{|l|}{$\mathrm{Pz}$} & \multicolumn{2}{|l|}{$\mathrm{Fz}$} & \multicolumn{2}{|l|}{$\mathrm{Cz}$} & \multicolumn{2}{|l|}{$\mathrm{Pz}$} & \multicolumn{2}{|l|}{$\mathrm{Fz}$} & \multicolumn{2}{|l|}{$\mathrm{Cz}$} & \multicolumn{2}{|l|}{$\mathrm{Pz}$} \\
\hline & & & Amp. & Lat. & Amp. & Lat. & Amp. & Lat. & Amp. & Lat. & Amp. & Lat. & Amp. & Lat. & Amp. & Lat. & Amp. & Lat. & Amp. & Lat. \\
\hline \multirow{4}{*}{ MMN } & \multirow{2}{*}{ Duration } & $\mathrm{HC}$ & $\begin{array}{l}-2.6 \pm \\
1.1(0.2)\end{array}$ & \begin{tabular}{|l|}
$204.3 \pm$ \\
29.3 \\
$(6.1)$ \\
\end{tabular} & $\begin{array}{l}-2.9 \pm \\
1.3 \\
(0.2)\end{array}$ & $\begin{array}{l}199.9 \pm \\
30.3 \\
(6.3)\end{array}$ & \begin{tabular}{|l|}
$-1.8 \pm$ \\
1.2 \\
$(0.2)$
\end{tabular} & \begin{tabular}{|l|}
$201.3 \pm$ \\
30.7 \\
$(6.4)$ \\
\end{tabular} & $\begin{array}{l}-3 \pm \\
1.5 \\
(0.3)\end{array}$ & \begin{tabular}{|l|}
$203.2 \pm$ \\
29.5 \\
$(6)$
\end{tabular} & $\begin{array}{l}-3 \pm \\
1.4 \\
(0.2)\end{array}$ & \begin{tabular}{|l|}
$204.3 \pm$ \\
27 \\
$(5.5)$
\end{tabular} & \begin{tabular}{|l|}
$-2.2 \pm$ \\
0.9 \\
$0.1)$ \\
\end{tabular} & \begin{tabular}{|l|}
$199.7 \pm$ \\
28.2 \\
$(5.7)$
\end{tabular} & \begin{tabular}{|l|}
$-3.1 \pm$ \\
1.8 \\
$(0.3)$
\end{tabular} & \begin{tabular}{|l|}
$206.1 \pm$ \\
27.1 \\
$(5.5)$ \\
\end{tabular} & \begin{tabular}{|l|}
$-3.2 \pm$ \\
1.5 \\
$(0.3)$
\end{tabular} & \begin{tabular}{|l|}
$204.5 \pm$ \\
23.9 \\
$(4.8)$
\end{tabular} & $\begin{array}{l}-2.3 \pm \\
1(0.2)\end{array}$ & $\begin{array}{l}202.6 \pm \\
25.4 \\
(5.1)\end{array}$ \\
\hline & & SCZ & $\begin{array}{l}-2 \pm \\
10(0.2)\end{array}$ & \begin{tabular}{l|}
$190.8 \pm$ \\
35.9 \\
$(8.2)$
\end{tabular} & $\begin{array}{l}-2 \pm \\
1(0.2)\end{array}$ & \begin{tabular}{l|}
$181.4 \pm$ \\
39.1 \\
$(8.7)$
\end{tabular} & \begin{tabular}{|l|}
$-1.8 \pm$ \\
1.2 \\
$(0.2)$ \\
\end{tabular} & \begin{tabular}{|l|}
$186.8 \pm$ \\
25.5 \\
$(5.8)$
\end{tabular} & \begin{tabular}{|l}
$-2 \pm$ \\
1.3 \\
$(0.3)$
\end{tabular} & \begin{tabular}{|l|}
$185 \pm$ \\
27.1 \\
$(6.0)$ \\
\end{tabular} & \begin{tabular}{|l|}
$-1.9 \pm$ \\
1.1 \\
$(0.2)$
\end{tabular} & \begin{tabular}{|l|}
$186.1 \pm$ \\
29.5 \\
$(6.2)$ \\
\end{tabular} & $\begin{array}{l}-1.1 \pm \\
1(0.2)\end{array}$ & \begin{tabular}{|l|}
$185.3 \pm$ \\
25.9 \\
$(5.8)$
\end{tabular} & $\begin{array}{l}-2.1 \pm \\
1.3 \\
(0.3)\end{array}$ & \begin{tabular}{|l|}
$186.8 \pm$ \\
32.6 \\
$(7.4)$ \\
\end{tabular} & \begin{tabular}{|l|}
$-2.2 \pm$ \\
1.7 \\
$(0.3)$ \\
\end{tabular} & \begin{tabular}{|l|}
$182.3 \pm$ \\
40.7 \\
$(8.9)$ \\
\end{tabular} & $\begin{array}{l}-2.4 \pm \\
2(0.5)\end{array}$ & $\begin{array}{l}174.1 \pm \\
34.9 \\
(8.0)\end{array}$ \\
\hline & \multirow{2}{*}{ Frequency } & $\mathrm{HC}$ & $\begin{array}{l}-3.1 \pm \\
1.5(0.3)\end{array}$ & \begin{tabular}{|l|}
$183.7 \pm$ \\
27 \\
$(5.6)$ \\
\end{tabular} & $\begin{array}{l}-3.2 \pm \\
1.8 \\
(0.3)\end{array}$ & $\begin{array}{l}180.6 \pm \\
2.7 \\
(4.9)\end{array}$ & \begin{tabular}{|l|}
$-2.4 \pm$ \\
1.3 \\
$(0.2)$
\end{tabular} & \begin{tabular}{|l|}
$184.9 \pm$ \\
31.3 \\
$(6.5)$ \\
\end{tabular} & \begin{tabular}{|l|}
$-2.9 \pm$ \\
1.3 \\
$(0.2)$
\end{tabular} & $\begin{array}{l}202 \pm \\
29(6)\end{array}$ & \begin{tabular}{|l|}
$-2.6 \pm$ \\
1.3 \\
$(0.2)$
\end{tabular} & $\begin{array}{l}188.2 \pm \\
34(7)\end{array}$ & $\begin{array}{l}-1.8 \pm \\
1(0.2)\end{array}$ & \begin{tabular}{|l|}
$176.9 \pm$ \\
38.5 \\
$(8)$
\end{tabular} & $\begin{array}{l}-4.4 \pm \\
1.4 \\
(0.3)\end{array}$ & \begin{tabular}{|l|}
$172.7 \pm$ \\
17.6 \\
$(3.6)$ \\
\end{tabular} & \begin{tabular}{|l|}
$-4.1 \pm$ \\
1.5 \\
$(0.3)$
\end{tabular} & \begin{tabular}{|l|}
$174.8 \pm$ \\
22 \\
$(4.5)$
\end{tabular} & $\begin{array}{l}-2.9 \pm \\
1.2(0.2)\end{array}$ & \begin{tabular}{|l|}
$176 \pm$ \\
24.3 \\
$(5)$
\end{tabular} \\
\hline & & SCZ & $\begin{array}{l}-2.1 \pm \\
1.6(0.4)\end{array}$ & \begin{tabular}{|l|}
$178.4 \pm$ \\
26.3 \\
$(6.8)$ \\
\end{tabular} & $\begin{array}{l}-1.8 \pm \\
1.5 \\
(0.3)\end{array}$ & $\begin{array}{l}169.6 \pm \\
26.5 \\
(6.6)\end{array}$ & \begin{tabular}{|l|}
$-1.5 \pm$ \\
1.2 \\
$(0.3)$ \\
\end{tabular} & \begin{tabular}{|l|}
$159.2 \pm$ \\
26.2 \\
$(6.7)$ \\
\end{tabular} & $\begin{array}{l}-2.3 \pm \\
1(0.2)\end{array}$ & \begin{tabular}{|l|}
$186.6 \pm$ \\
34.7 \\
$(8.6)$
\end{tabular} & \begin{tabular}{|l|}
$-2.1 \pm$ \\
1.4 \\
$(0.3)$
\end{tabular} & \begin{tabular}{|l|}
$182.2 \pm$ \\
288 \\
$(7.0)$
\end{tabular} & \begin{tabular}{|l|}
$-1.7 \pm$ \\
1.5 \\
$(0.3)$
\end{tabular} & \begin{tabular}{|l|}
$172.6 \pm$ \\
36.5 \\
$(9.1)$
\end{tabular} & \begin{tabular}{|l|}
$-3.5 \pm$ \\
1.4 \\
$(0.3)$
\end{tabular} & \begin{tabular}{|l|}
$174.1 \pm$ \\
24.8 \\
$(6)$
\end{tabular} & \begin{tabular}{|l|}
$-3 \pm$ \\
1.1 \\
$(0.2)$
\end{tabular} & $\begin{array}{l}171.3 \pm \\
20.9 \\
(4.9)\end{array}$ & $\begin{array}{l}-2.1 \pm \\
0.8(0.2)\end{array}$ & \begin{tabular}{|l|}
$166.5 \pm$ \\
26.5 \\
$(6.4)$
\end{tabular} \\
\hline \multirow{2}{*}{ P3a } & & $\mathrm{HC}$ & $\begin{array}{l}10.7 \pm \\
3.8(0.7)\end{array}$ & \begin{tabular}{|l|}
$340.1 \pm$ \\
43.2 \\
$(8.8)$ \\
\end{tabular} & $\begin{array}{l}12.0 \pm \\
4.1 \\
(0.8)\end{array}$ & $\begin{array}{l}323 \pm \\
41.7 \\
(8.5)\end{array}$ & $\begin{array}{l}9.8 \pm \\
3.6 \\
(0.7)\end{array}$ & \begin{tabular}{|l|}
$346.5 \pm$ \\
37.6 \\
$(7.6)$
\end{tabular} & \begin{tabular}{|l|}
$9.2 \pm$ \\
4.0 \\
$(0.8)$
\end{tabular} & \begin{tabular}{|l|}
$335.1 \pm$ \\
45.2 \\
$(9.4)$
\end{tabular} & \begin{tabular}{|l|}
$10.3 \pm$ \\
4.3 \\
$(0.9)$
\end{tabular} & \begin{tabular}{|l|}
$333.7 \pm$ \\
41.1 \\
$(8.5)$
\end{tabular} & $\begin{array}{l}9.0 \pm \\
3.2 \\
(0.6)\end{array}$ & \begin{tabular}{|l|}
$342 \pm$ \\
45.9 \\
$(9.5)$
\end{tabular} & $\begin{array}{l}9.6 \pm \\
5.1(1)\end{array}$ & $\begin{array}{l}343.3 \pm \\
32.4 \\
(6.7)\end{array}$ & $\begin{array}{l}10.7 \pm \\
5(1)\end{array}$ & \begin{tabular}{|l|}
$334.1 \pm$ \\
34.5 \\
$(7.1)$ \\
\end{tabular} & $\begin{array}{l}8.5 \pm 3.5 \\
(0.7)\end{array}$ & \begin{tabular}{|l}
$356.6 \pm$ \\
43 \\
$(8.9)$
\end{tabular} \\
\hline & & SCZ & $5.6 \pm 2.9$ & \begin{tabular}{|l|}
$353.9 \pm$ \\
53.8
\end{tabular} & $\begin{array}{l}6.5 \pm \\
3.3\end{array}$ & $\begin{array}{l}343.1 \pm \\
56.2\end{array}$ & $\begin{array}{l}5.9 \pm \\
2.9\end{array}$ & $\begin{array}{l}363.1 \pm \\
57\end{array}$ & $\begin{array}{l}5.7 \pm \\
2.8 \\
(0.5)\end{array}$ & \begin{tabular}{|l|}
$357.1 \pm$ \\
64.3 \\
$(13.4)$ \\
\end{tabular} & \begin{tabular}{|l|}
$6.8 \pm$ \\
3.5 \\
$(0.7)$ \\
\end{tabular} & \begin{tabular}{|l|}
$355.8 \pm$ \\
53.7 \\
$(11.1)$
\end{tabular} & \begin{tabular}{|l|}
$5.9 \pm$ \\
3.2 \\
$(0.6)$
\end{tabular} & $\begin{array}{l}374.6 \pm \\
46.7 \\
(9.7)\end{array}$ & $\begin{array}{l}5.8 \pm \\
3.4 \\
(0.6)\end{array}$ & \begin{tabular}{|l|}
$357.6 \pm$ \\
63.9 \\
$(13)$ \\
\end{tabular} & $\begin{array}{l}6.7 \pm \\
3.2 \\
(0.6)\end{array}$ & \begin{tabular}{|l|}
$356 \pm$ \\
64.5 \\
$(13.1)$
\end{tabular} & \begin{tabular}{|l|}
$5.7 \pm 2.4$ \\
$(0.5)$
\end{tabular} & \begin{tabular}{|l|}
$371.9 \pm$ \\
63.9 \\
$(13)$
\end{tabular} \\
\hline \multirow{3}{*}{ P3b } & & Region & \multicolumn{2}{|l|}{$\mathrm{Pz}$} & \multicolumn{2}{|l|}{ P3 } & \multicolumn{2}{|l|}{$\mathrm{P} 4$} & \multicolumn{2}{|l|}{$\mathrm{Pz}$} & \multicolumn{2}{|l|}{ P3 } & \multicolumn{2}{|l|}{$\mathrm{P} 4$} & \multicolumn{2}{|l|}{$\mathrm{Pz}$} & \multicolumn{2}{|l|}{ P3 } & \multicolumn{2}{|l|}{$\mathrm{P} 4$} \\
\hline & & $\mathrm{HC}$ & $\begin{array}{l}8.4 \pm \\
3.8(0.7)\end{array}$ & \begin{tabular}{|l|}
$384.3 \pm$ \\
54.4 \\
$(11.1)$
\end{tabular} & \begin{tabular}{|l|}
$7.4 \pm$ \\
3.7 \\
$(0.7)$
\end{tabular} & \begin{tabular}{|l|}
$388.2 \pm$ \\
55.7 \\
$(11.3)$ \\
\end{tabular} & \begin{tabular}{|l|}
$7.4 \pm$ \\
3.5 \\
$(0.7)$
\end{tabular} & \begin{tabular}{|l|}
$385.1 \pm$ \\
58.5 \\
$(11.9)$ \\
\end{tabular} & $\begin{array}{l}9.1 \pm \\
3.8 \\
(0.8)\end{array}$ & \begin{tabular}{|l|}
$387.8 \pm$ \\
53.1 \\
$(11.0)$
\end{tabular} & $\begin{array}{l}8 \pm 3.8 \\
(0.8)\end{array}$ & \begin{tabular}{|l|}
$390.2 \pm$ \\
44.9 \\
$(9.3)$
\end{tabular} & \begin{tabular}{|l|}
$8.2 \pm$ \\
3.3 \\
$(0.6)$
\end{tabular} & $\begin{array}{l}393.0 \pm \\
51.7 \\
(10.7)\end{array}$ & $\begin{array}{l}8.4 \pm \\
3.5 \\
(0.7)\end{array}$ & \begin{tabular}{|l|}
$377 \pm$ \\
67.4 \\
$(14)$
\end{tabular} & $\begin{array}{l}7.1 \pm \\
3.2 \\
(0.6)\end{array}$ & \begin{tabular}{|l|}
$396 \pm$ \\
62.3 \\
$(12.9)$
\end{tabular} & \begin{tabular}{|l|}
$7.7 \pm 3.5$ \\
$(0.7)$
\end{tabular} & \begin{tabular}{|l|}
$374 \pm$ \\
68.2 \\
$(14.2)$
\end{tabular} \\
\hline & & SCZ & $\begin{array}{l}4.4 \pm \\
2.3(0.4)\end{array}$ & \begin{tabular}{|l|}
$416.4 \pm$ \\
80.7 \\
$(16.8)$ \\
\end{tabular} & $\begin{array}{l}3.8 \pm \\
1.7 \\
(0.3)\end{array}$ & \begin{tabular}{|l|}
$410.6 \pm$ \\
74.7 \\
$(15.5)$
\end{tabular} & $\begin{array}{l}3.7 \pm \\
1.8 \\
(0.3)\end{array}$ & \begin{tabular}{|l|}
$401.8 \pm$ \\
89 \\
$(18.5)$ \\
\end{tabular} & $\begin{array}{l}4.3 \pm \\
2.6 \\
(0.5)\end{array}$ & \begin{tabular}{|l|}
$432.5 \pm$ \\
85.7 \\
$(17.8)$ \\
\end{tabular} & $\begin{array}{l}3.6 \pm \\
2.6 \\
(0.5)\end{array}$ & $\begin{array}{l}409 \pm \\
79.4 \\
(16.5)\end{array}$ & $\begin{array}{l}4.1 \pm \\
2.3 \\
(0.4)\end{array}$ & $\begin{array}{l}419.8 \pm \\
71.4 \\
(14.8)\end{array}$ & \begin{tabular}{|l|}
$4.4 \pm$ \\
2.4 \\
$(0.5)$
\end{tabular} & \begin{tabular}{|l|}
$451.8 \pm$ \\
85.8 \\
$(17.5)$ \\
\end{tabular} & $\begin{array}{l}3.8 \pm \\
2.3 \\
(0.4)\end{array}$ & \begin{tabular}{|l|}
$450.5 \pm$ \\
85.4 \\
$(17.4)$
\end{tabular} & $\begin{array}{l}4.3 \pm 1.7 \\
(0.3)\end{array}$ & \begin{tabular}{|l|}
$444.4 \pm$ \\
90.1 \\
$(18.3)$
\end{tabular} \\
\hline
\end{tabular}

Table 2. ERP mean amplitude and latency of HCs and SCZ patients in electrode regions $[\mathrm{M} \pm \mathrm{SD}(\mathrm{SE})]$.

sensitive to parietal lobe lesions ${ }^{38}$. The frontal and temporal lobes may thus be bilaterally involved in SCZ. In contrast to research reports of right- ${ }^{15}$ or leftward ${ }^{39}$ bias in the sensorium, some findings pointed to a lack of asymmetry in $\mathrm{MMN}^{40}$ or $\mathrm{P}^{16,20,41}$ responses to dichotic stimuli. These inconsistent results may have stemmed from differences in patient samples among different laboratories ${ }^{42-44}$. Simple ERP tasks may not effectively uncover asymmetric language-related dysfunctions in SCZ, thus highlighting the need for more complex and demanding tasks containing more phonological content ${ }^{20,45}$.

Switching attention to a change in an incoming signal is accomplished through a set of responses: N1 as the index of transient detection, MMN for sensory-memory-based change detection, P3a for involuntary attention orientation, and eventually, the task-related voluntary response or $\mathrm{P} 3 \mathrm{~b}^{46-48}$. Although dissociated in mechanisms $s^{20,35,49}$, these brain waves play complementary roles in the aforementioned shift in attention ${ }^{48}$. The symmetric deficits of ERP responses to different sound directions in the present work could be an indicator of pervasive deficits in change detection systems, which are responsible for both bottom-up (MMN) and top-down (P3) processes ${ }^{50}$. Nevertheless, this pattern of findings does not mean that spatial processing abnormalities are nonexistent in SCZ patients. Such pattern can be interpreted as being related to some nonlateralized dysfunctions in spatial processing.

Two perspectives have been proposed to explain spatial attention bias: the first is the well-known concept of lateralized deficits, which suggest that brain dysfunction in one hemisphere affects the contralesional hemispace $^{51,52}$, and the second is the issue of non-lateralized impairments, at which the spatial deficits might not necessarily worsen toward one side of a space ${ }^{13}$. Researchers have also argued that such a whole space deficit can be related to the ACC hypofunction in $\mathrm{SCZ}^{28,29}$.

Interestingly, spatial processing deficits may involve not only attending to stimuli but also ignoring stimuli from different locations. As demonstrated in a previous study, SCZ patients failed to filter peripheral (right vs. left) stimuli when they were required to focus centrally ${ }^{1}$. In line with our findings, the researchers reported no difference between HCs and SCZ patients in ignoring outer peripheral stimuli. They attributed this observation to a hyperfocusing of attention to central locations of the sensorium in SCZ individuals, along with a disability to distribute attention broadly to the periphery.

Another potential cause of the symmetric pattern of brain responses in the current study are plastic changes in the brain during the course of SCZ ${ }^{48}$. Hypoactivation of the left hemisphere, including the left temporal lobe, is a frequent occurrence in schizophrenic patient ${ }^{53,54}$, and this condition can progress, be altered, or be reversed during the course of the disease ${ }^{55}$. Therefore, temporal lobe functions, including spatial coding, may alter during the course of disease. As a compensatory reaction, the brain may decrease the right STG activation with the course of the disease; hence, a symmetrical hypoactivation takes place, as was observed in the present work.

To the best of our knowledge, this research is the first to use a dichotic listening paradigm in examining the spatial correlates of auditory attention among SCZ patients and assess auditory spatial functions at multiple levels of consciousness. On the basis of the sequential model of auditory perception ${ }^{56}$, the perceptual segregation and spatial localization of auditory objects are the prerequisites of higher-order auditory processes, including dichotic listening paradigms ${ }^{57}$. Given the sensitivity of dichotic listening tasks to auditory stream segregation and fusion, they can serve as a valuable tool for spatial processing in ERP studies ${ }^{58-60}$. Another methodological strength of the present work was the sound field testing, which more closely approximates real-world situations than does tests involving ear covering. An ideal improvement to this approach would be to conceal sound sources to eliminate visual cues. 
The limitations of this study are worth noting. First, all the patients were taking their medications, which might have affected the results. Future studies should examine auditory processing across a group of drug-naive patients and patients with different subtypes of SCZ. Second, the patient group was recruited mainly from an outpatient clinic and showed mild symptoms. Thus, they may not exactly represent individuals typically encountered in clinical practice or examined in previous SCZ studies, thereby potentially limiting the generalizability of the findings. Note that it would be helpful if patients at different stages of SCZ (for example, in the groups of first episode and chronic patients, or in the form of longitudinal surveys) be involved in such evaluations, which helps the researchers to study changes during the disease. Concerning the potential effect of the medicines on the disease course, similar research may help to understand their long-lasting effects on the patients' functions, as an invaluable source for promoting the policies of medical therapy in SCZ patients. Moreover, specifying the characteristics and pattern of spatial processing deficits in SCZ helps the therapists in developing beneficial cognitive therapies for these patients. For example, if the SCZ patients underestimated the peripheral (right and left) stimuli, but focused intensely on the stimuli from the midline of the sensorium, it might be possible to suggest a rehabilitative plan to balance this abnormal spatial function.

Conclusively, using pre-attentional and attention-dependent measures, we found deficits in detecting, orienting, and responding to changes in auditory sensory inputs among the SCZ patients. This phenomenon is most probably related to a general hypofunction rather than a lateralized bias in response to different stimulus directions.

\section{Methods}

Participants. Thirty-five right-handed outpatient schizophrenic patients whose characteristics corresponded with the DSM IV (Diagnostic and Statistical Manual of Mental Disorders, fourth edition) criteria for SCZ were assessed using the positive and negative symptom scale ${ }^{61}$. The patients did not have a history of electroconvulsive therapy within six months prior to the testing period. They were receiving their medications at the time of testing at a mean chlorpromazine equivalent dose of $457 \mathrm{mg} / \mathrm{Kg}$.

The control group was composed of 35 right-handed healthy individuals who were screened for personal and family histories of psychotic illnesses. The exclusion criteria were a history of neurological disorders and head injury as well as current substance abuse. All the participants were assessed via behavioral audiometry (based on the modified Hughson-Westlake procedure) configured to four frequency octave bands $(0.5,1,2$, and $4 \mathrm{KHz})$. Normal hearing was defined as hearing thresholds $\leq 25 \mathrm{~dB}$. Each subject was paid US $\$ 20$ participation fee.

The study was conducted under the principles of the Declaration of Helsinki for Biomedical Research. Accordingly, written informed consent was obtained from all the participants, and the study was approved by the Ethics Committee of Kerman University of Medical Sciences.

Assessment procedures. All the experiments were performed in a sound-proof, dimly lit chamber with ambient noise levels that satisfied the ANSI S3.1-1999 standards for audiometry chambers. The sound stimuli included pure tones, which were presented from one or two speakers located at the ear level (distance from the head center: $90 \mathrm{~cm}$, hearing angle: $\pm 90^{\circ}$ azimuth) and covered with suitable curtains. The participants were seated comfortably, with their head fixed in a relaxed posture on a chin rest. The sequence of tasks, which were designed using PsyTask version 1.53.17 (Mitsar Inc., Russia), was counterbalanced across the participants.

MMN recording. The participants were instructed to silently watch a wildlife movie on a monitor (distance from eyes: $80 \mathrm{~cm}$, visual angle: $5^{\circ}$ on each side from the mid-sagittal plane) and disregard sounds. Each block consisted of 1500 stimuli, including 150 rare (deviant) and 1350 frequent (standard) tones (deviance probability: 10\%). Each trial was characterized by $50 \mathrm{~ms}$ of pre-stimulus time, $50 \mathrm{~ms}$ (or $100 \mathrm{~ms}$ for duration deviants) of stimulus presentation, $150 \mathrm{~ms}$ of interstimulus intervals (ISIs), and a sequential interdeviant interval of 9 (with each successive deviant disrupted by 5 to 13 standards). Regarding the previous reports of different response patterns to frequency vs duration deviance in SCZ studies ${ }^{62}$, both paradigms were implemented in the present work. With respect to duration MMN, the unilateral stimuli were tones with a frequency of $600 \mathrm{~Hz}$, each presented for $50 \mathrm{~ms}$ (as standard stimuli) and $100 \mathrm{~ms}$ (as deviants), once from the right side and once again from the left. Bilateral stimuli were a pair of tones, once with a frequency of $740 \mathrm{~Hz}$ that were always presented from the left and another tone with a frequency of $932 \mathrm{~Hz}$ that was always presented from the right. These tones were presented for $50 \mathrm{~ms}$ (as standard stimuli) and $100 \mathrm{~ms}$ (as deviant stimuli). The tasks were designed with consideration of the works of Deouell et al..$^{63}$ and Kayser et al..$^{20}$.

With regard to frequency MMN, the unilateral stimuli were $485 \mathrm{~Hz}$ tones as the standards and $444 \mathrm{~Hz}$ as the deviants (with each pair presented once from the right and once from the left). In dichotic stimulation, a $740 \mathrm{~Hz}$ tone from the left and a $932 \mathrm{~Hz}$ tone from the right were presented as standard stimuli, and a $660 \mathrm{~Hz}$ tone from the left and a $830 \mathrm{~Hz}$ tone from the right were presented as deviant stimuli, all at a duration of $50 \mathrm{~ms}$. All the bilateral (dichotic) stimuli were $6 \mathrm{~dB}$ weaker in intensity compared with the unilateral stimuli.

P3 recording. A three-stimulus oddball paradigm was applied in P3 elicitation. Each block consisted of 600 stimuli, namely, 60 targets (probability: $5 \%$ ), 60 familiar stimuli, environmental novels ${ }^{64,65}$ (probability: 5\%), and 480 standard tones. Each trial was characterized by $100 \mathrm{~ms}$ of pre-stimulus time, $250 \mathrm{~ms}$ of stimulus duration, and $1 \mathrm{~s}$ of ISI. Every successive target was disrupted by 2 to 5 standards. In the unilateral tests, a $1 \mathrm{KHz}$ tone was used as a standard stimulus, and a $1.5 \mathrm{KHz}$ tone was employed as the target (each presented once from the right and once from the left). In the dichotic tests, a $444 \mathrm{~Hz}$ tone from the left combined with a $485 \mathrm{~Hz}$ tone from the right was adopted as a standard stimulus, and a $1084 \mathrm{~Hz}$ tone originating from the left paired with a $1125 \mathrm{~Hz}$ tone coming from the right was used (the novel sound was also played dichotically). This noticeable frequency difference between standard and deviant stimuli in P3 task (compared with the MMN recording paradigm) was considered according to previous reports of frequency discrimination problems in some SCZ patients ${ }^{66}$. The participants were instructed to ignore the novel sounds and press the space bar of a keyboard when they hear a high-pitched tone. 
ERP acquisition. Electroencephalography (EEG) data were recorded and analyzed using a 32-channel Win EEG System (version 2.126.97, Mitsar Inc., Russia), with a sampling rate of $250 \mathrm{~Hz}$, a low-pass filter off $0.1 \mathrm{~Hz}$, a high-pass filter of $45 \mathrm{~Hz}$, and band notch of 45 to $55 \mathrm{~Hz}$. Electrode impedances were kept below $5 \mathrm{k} \Omega$.

The raw EEG was recorded to the database using monopolar montage in relation to reference electrodes (average reference). The EEG was then reformatted and filtered according to the montage parameters (it can be modified by the command: Setup $>$ Montage List) into the selected montage (monopolar $1 \mathrm{~A} 1<->\mathrm{A} 2$ ), and the data were re-referenced offline to linked ear lobes.

Motion correction was performed in 4 steps: 1 . Visual monitoring of the raw EEG and removing the noisy trials manually. The noisy trials were selected based on their very large amplitude (for muscle artifacts, usually over $100 \mu \mathrm{v}$ ) and their morphology. 2. Removing the eye blinks (in the Win EEG software it can be done by deselecting the Bio channel in the "change montage" tab). 3. Selecting a clean, well recorded piece of EEG (about 180 trials), as a sample. 4. Running independent component analysis (ICA) through this command: Analyze tab > Artifacts correction. In case of noisy channels, as we monitored the EEG recording online, it was possible to detect the presence of any constant noise in a special channel. In this case, the recording was paused and the noise source (usually, the myogenic activity caused by frowning) was amended. Hence, we had not any "bad channel" in our records to be removed.

The minimum number of clean trials needed for EEG analysis were $70 \%$ of all of testing trials (in case of P3 recordings: 490 trials, and for MMN recordings: 735 trials). However, we were usually more cautious that this, as we did not reject more than $20 \%$ of trials.

After artifact rejection, ERPs were averaged relative to stimulus onset, which covered $100 \mathrm{~ms}$ of pre-stimulus time to $700 \mathrm{~ms}$ of post-stimulus. MMN was identified as the largest negative valley in the latency range of 110 to $250 \mathrm{~ms}$ at mid-sagittal electrodes ( $\mathrm{Fz}, \mathrm{Cz}$, and $\mathrm{Pz})$. P3a and $\mathrm{P} 3 \mathrm{~b}$ components were defined as the largest peaks in the latency range of 230 to $450 \mathrm{~ms}$ and 300 to $600 \mathrm{~ms}$ after stimulus onset, respectively. Fz, F3, F4, Cz, and Pz electrodes were selected for $\mathrm{P} 3 \mathrm{a}$ analysis, and parietal electrodes $(\mathrm{P} 3, \mathrm{Pz}$, and $\mathrm{P} 4)$ were selected for $\mathrm{P} 3 \mathrm{~b}$ analysis.

Statistical analyses. A repeated measure analysis of variance (ANOVA) was conducted to test for the effects of two within subjects' factor: 1 . The stimulus location (three levels: unilateral right, unilateral left and bilateral stimulation) and 2. The electrode site (three levels, as described above). Significant main effects, interactions, and follow-up pairwise comparisons were examined after adjustment for multiple testing (Bonferroni). A combination of chi-square tests and t-tests were used on demographic and clinical data. All the analyses were conducted using the Statistical Package for the Social Sciences version 20.

The sample size was determined based on similar previous studies ${ }^{15,20}$. The power analysis was performed using the $\mathrm{G}^{*}$ power software to determine the number of subjects that would have been needed to indicate the difference in amplitude and latencies $(\alpha=5 \%$ and power $=80 \%)$.

\section{Data availability}

The datasets generated and/or analyzed during the study are available from the corresponding author upon request.

Received: 18 July 2018; Accepted: 26 October 2019;

Published online: 11 November 2019

\section{References}

1. Kreither, J. et al. Electrophysiological Evidence for Hyperfocusing of Spatial Attention in Schizophrenia. J. Neurosci. 37, 3813-3823 (2017).

2. Dalmaso, M., Galfano, G., Tarqui, L., Forti, B. \& Castelli, L. Is social attention impaired in schizophrenia? Gaze, but not pointing gestures, is associated with spatial attention deficits. Neuropsychology 27, 608-613 (2013).

3. Rund, B. R. \& Borg, N. E. Cognitive deficits and cognitive training in schizophrenic patients: a review. Acta Psychiatr. Scand. 100, 85-95 (1999).

4. Michel, C. et al. Pseudoneglect in schizophrenia: A line bisection study with cueing. Cogn. Neuropsychiatry 12, 222-234 (2007).

5. Liu, Y.-C., Chen, K.-C., Yang, Y. K., Chen, Y.-L. \& Lin, K.-C. Relationship between Hemispatial Inattention and Performance of Activities of Daily Living in Patients with Schizophrenia. Percept. Mot. Skills 112, 703-710 (2011).

6. Pourrahimi, A. M., Mazhari, S., Shabani, M. \& Sheibani, V. An evidence for lack of pseudoneglect in patients with schizophrenia: An ERP study. Neurosci. Lett. 561, 96-100 (2014).

7. Ribolsi, M., Daskalakis, Z. J., Siracusano, A. \& Koch, G. Abnormal Asymmetry of Brain Connectivity in Schizophrenia. Front. Hum. Neurosci. 8, 1-11 (2014).

8. Ozel-Kizil, E. T., Baskak, B., Gunes, E., Cicek, M. \& Atbasoglu, E. C. Hemispatial neglect evaluated by visual line bisection task in schizophrenic patients and their unaffected siblings. Psychiatry Res. 200, 133-136 (2012).

9. Zimmer, U., Lewald, J. \& Karnath, H.-O. Disturbed Sound Lateralization in Patients with Spatial Neglect. J. Cogn. Neurosci. 15, 694-703 (2003)

10. Cavézian, C. et al. Visuospatial processing in schizophrenia: Does it share common mechanisms with pseudoneglect? Laterality 16, 433-461 (2011).

11. Vafaii, P., Pourrahimi, A. M., Nakhaee, N. \& Mazhari, S. Anti-Extinction in Patients With Schizophrenia, https://doi.org/10.5812/ ijpbs.9185. Original (2018).

12. Dierks, T. et al. Activation of Heschl's Gyrus during Auditory Hallucinations. Neuron 22, 615-621 (1999).

13. Husain, M. \& Rorden, C. Non-spatially lateralised mechanisms in hemispatial neglect. Nat. Rev. Neurosci. 4, 26-36 (2005).

14. Näätänen, R., Todd, J. \& Schall, U. Mismatch negativity (MMN) as biomarker predicting psychosis in clinically at-risk individuals. Biol. Psychol. 116, 36-40 (2016).

15. Deouell, L. Y., Bentin, S. \& Soroker, N. Electrophysiological evidence for an early (pre-attentive) information processing deficit in patients with right hemisphere damage and unilateral neglect. Brain 123, 353-365 (2000).

16. Perrin, M. A. et al. Mismatch negativity (MMN) to spatial deviants and behavioral spatial discrimination ability in the etiology of auditory verbal hallucinations and thought disorder in schizophrenia. Schizophr. Res. 191, 140-147 (2017).

17. Näätänen, R. et al. The mismatch negativity (MMN) - A unique window to disturbed central auditory processing in ageing and different clinical conditions. Clin. Neurophysiol. 123, 424-458 (2012). 
18. Devrim-Üçok, M., Yasemin Keskin-Ergen, H. \& Üçok, A. Novelty P3 and P3b in first-episode schizophrenia and chronic schizophrenia. Prog. Neuro-Psychopharmacology Biol. Psychiatry 30, 1426-1434 (2006).

19. Sussman, E. S. A New View on theMMN and Attention Debate: The Role of Context in Processing Auditory Events. J. Psychophysiol. 21, 164-175 (2007).

20. Kayser, J. et al. Event-related brain potentials (ERPs) in schizophrenia for tonal and phonetic oddball tasks. Biol. Psychiatry 49, 832-847 (2001)

21. Wright, I. C. et al. Meta-Analysis of Regional Brain Volumes in Schizophrenia. Am. J. Psychiatry 157, 16-25 (2000).

22. Satomi, K., Horai, T., Kinoshita, Y. \& Wakazono, A. Hemispheric asymmetry of event-related potentials in a patient with callosal disconnection syndrome: a comparison of auditory, visual and somatosensory modalities. Electroencephalogr. Clin. Neurophysiol. 94, 440-449 (1995).

23. Zugman, A. et al. Reduced dorso-lateral prefrontal cortex in treatment resistant schizophrenia. Schizophr. Res. 148, 81-86 (2013).

24. Kaphingst, K. A., Persky, S. \& Lachance, C. A review of MRI findings in schizophrenia. Schizophr Res. 14, 384-399 (2010).

25. Leicht, G. et al. Reduced Early Auditory Evoked Gamma-Band Response in Patients with Schizophrenia. Biol. Psychiatry 67, 224-231 (2010)

26. Snitz, B. E. et al. Lateral and medial hypofrontality in first-episode schizophrenia: functional activity in a medication-naïve state and effects of short-term atypical antipsychotic treatment. Am. J. Psychiatry 162, 2322-2329 (2005).

27. Eisenberg, D. P. \& Berman, K. F. Executive function, neural circuitry, and genetic mechanisms in schizophrenia. Neuropsychopharmacology 35, 258-277 (2010).

28. Carter, C. S., Mintun, M., Cohen, J. D. \& Nichols, T. Anterior cingulate gyrus dysfunction and selective attention dysfunction in schizophrenia. Am. J. Psychiatry (1998).

29. Geoffrey, W. \& Stephen, J. Anterior cingulate activation during Stroop task performance: A PET... (2002).

30. Takahashi, H. et al. Neural substrates of normal and impaired preattentive sensory discrimination in large cohorts of nonpsychiatric subjects and schizophrenia patients as indexed by MMN and P3a change detection responses. Neuroimage 66, 594-603 (2013).

31. Higuchi, Y. et al. Mismatch Negativity and P3a/Reorienting Complex in Subjects with Schizophrenia or At-Risk Mental State. Front. Behav. Neurosci. 8, 1-10 (2014).

32. A.M.L, C. Neural generators of the auditory P3a and P3b revealed by ERPs and LORETA. Front. Hum. Neurosci. 2 (2008).

33. Heinrichs, R. W. \& Awad, A. G. Neurocognitive subtypes of chronic schizophrenia. Schizophr. Res. 9, 49-58 (1993).

34. Ford, J. M. et al. The Relationship Between P300 Amplitude and Regional Gray Matter Volumes Depends Upon the Attention System Engaged. Electroencephalogr. Clin. Neurophysiol. 90, 214-228 (1994).

35. Bachiller, A. et al. Auditory P3a and P3b neural generators in schizophrenia: An adaptive sLORETA P300 localization approach. Schizophr. Res. 169, 318-325 (2015).

36. Pae, J. S. et al. LORETA imaging of P300 in schizophrenia with individual MRI and 128-channel EEG. Neuroimage 20, 1552-1560 (2003).

37. Liddle, P. F., Kiehl, Ka \& Smith, aM. Event-related fMRI study of response inhibition. Hum. Brain Mapp. 12, 100-109 (2001).

38. Kolb, B. \& Whishaw, I. Q. Performance of schizophrenic patients on tests sensitive to left or right frontal, temporal, or parietal function in neurological patients. Journal of Nervous and Mental Disease 171, 435-443 (1983).

39. Javitt, D. C., Doneshka, P., Zylberman, I., Ritter, W. \& Vaughan, H. G. Impairment of early cortical processing in schizophrenia: An event-related potential confirmation study. Biol. Psychiatry 33, 513-519 (1993).

40. Kasai, K. et al. Mismatch negativity and N2b attenuation as an indicator for dysfunction of the preattentive and controlled processing for deviance detection in schizophrenia: A topographic event-related potential study. Schizophr. Res. 35, 141-156 (1999).

41. Potential, E., Evidence, B., Phonetic, F., Dichotic, T. \& Tasks, L. Left Temporal Lobe Dysfunction in Schizophrenia, 56, 267-276 (2013).

42. Ford, J. M. et al. ERPs in schizophrenia: Effects of antipsychotic medication. Biol. Psychiatry 36, 153-170 (1994).

43. Zhang, T., Koutsouleris, N., Meisenzahl, E. \& Davatzikos, C. Heterogeneity of structural brain changes in subtypes of schizophrenia revealed using magnetic resonance imaging pattern analysis. Schizophr. Bull. 41, 74-84 (2015).

44. Olabi, B. et al. Are there progressive brain changes in schizophrenia? a meta-analysis of structural magnetic resonance imaging studies. Biol. Psychiatry 70, 88-96 (2011).

45. Kayser j., Tenke C., Gil, R. \& Bruder, G. E. ERP Generator Patterns in Schizophrenia During Tonal and Phonetic Oddball Tasks. Effects of Response Hand and Silent count., 7, 221-229 (2005).

46. Näätänen, R. The role of attention in auditory information processing as revealed by event-related potentials and other brain measures of cognitive function. Behav Brain Sci 13, 201-208 (1990).

47. Näätänen, R. Attention and Brain Function. (Hills- dale, 1992).

48. Horváth, J., Winkler, I. \& Bendixen, A. Do N1/MMN, P3a, and RON form a strongly coupled chain reflecting the three stages of auditory distraction? Biol. Psychol. 79, 139-147 (2008).

49. Polich, J. Updating P300: An integrative theory of P3a and P3b. Clin. Neurophysiol. 118, 2128-2148 (2007)

50. Escera, C. \& Corral, M. J. Role of mismatch negativity and novelty-P3 in involuntary auditory attention. J. Psychophysiol. 21 (2007).

51. Ruff, R. M., Hersh, N. A. \& Pribram, K. H. Auditory Spatial Deficits in the Personal and Frames of Reference Due To Cortical Lesions., 19, 435-443 (1981).

52. Spierer, L., Meuli, R. \& Clarke, S. Extinction of auditory stimuli in hemineglect: Space versus ear. Neuropsychologia 45, 540-551 (2007).

53. Potential, E., Evidence, B., Phonetic, F., Dichotic, T. \& Tasks, L. Left Temporal Lobe Dysfunction in Schizophrenia- Event-Related Potential and Behavioral Evidence From Phonetic and Tonal Dichotic Listening Tasks., 56, 267-276 (2013).

54. Sommer, I., Aleman, A., Ramsey, N., Bouma, A. \& Kahn, R. Handedness, language lateralisation and anatomical asymmetry in schizophrenia: Meta-analysis. Br. J. Psychiatry 178, 344-351 (2001).

55. Keshavan, M. S. et al. Superior temporal gyrus and the course of early schizophrenia.pdf.

56. Bregman, A. S. \& McAdams, S. Auditory scene analysis: The perceptual organization of sound. J. Acoust. Soc. Am. 95, 1177-1178 (1994).

57. Bregman, A. Auditory Scene Analysis: The Perceptual Organization of Sound, https://doi.org/10.1121/1.408434 (2014).

58. Johnson, B. W., Hautus, M. \& Clapp, W. C. Neural activity associated with binaural processes for the perceptual segregation of pitch. Clin. Neurophysiol. 114, 2245-2250 (2003).

59. Johnson, B. W., Hautus, M. J., Duff, D. J. \& Clapp, W. C. Sequential processing of interaural timing differences for sound source segregation and spatial localization: Evidence from event-related cortical potentials. Psychophysiology 44, 541-551 (2007).

60. Brancucci, A. \& Tommasi, L. 'Binaural rivalry': Dichotic listening as a tool for the investigation of the neural correlate of consciousness. Brain Cogn. 76, 218-224 (2011).

61. Watson, D., Clark, L. A. \& Tellegen, A. Development and validation of brief measures of positive and negative affect: The PANAS scales. J. Pers. Soc. Psychol. 54, 1063-1070 (1988).

62. Michie, P. T., Budd, T. W., Todd, J., Rock, D. \& Wichmann, H. Duration and frequency mismatch negativity in schizophrenia., 111, 1054-1065 (2000).

63. Deouell, L. Y., Bentin, S. \& Giard, M. Mismatch negativity in dichotic listening: Evidence for interhemispheric differences and multiple generators. 355-365 (1998) 
64. Matthews, N., Todd, J., Budd, T. W., Cooper, G. \& Michie, P. T. Auditory lateralization in schizophrenia - Mismatch negativity and behavioral evidence of a selective impairment in encoding interaural time cues. Clin. Neurophysiol. 118, 833-844 (2007).

65. Escera, C., Yago, E. \& Corral, M. Attention capture by auditory significant stimuli: semantic analysis follows attention switching. Eur. J. (2003).

66. Rojas, D. C., Slason, E., Teale, P. D. \& Reite, M. L. Neuromagnetic evidence of broader auditory cortical tuning in schizophrenia. Schizophr Res. 8, 4017-4018 (2010).

\section{Acknowledgements}

This research was supported by the Neuroscience Research Center of Kerman University of Medical Science in Kerman, Iran. We especially thank Professor Leon Deouell, Charles Escera, and other specialists who kindly helped us in this work.

\section{Author contributions}

S.M. designed the study and revised the manuscript; A.M.P. and H.T. designed the tasks; S.S collected the data and drafted the manuscript. All the authors read the manuscript and approved it.

\section{Competing interests}

The authors declare no competing interests.

\section{Additional information}

Correspondence and requests for materials should be addressed to S.M.

Reprints and permissions information is available at www.nature.com/reprints.

Publisher's note Springer Nature remains neutral with regard to jurisdictional claims in published maps and institutional affiliations.

Open Access This article is licensed under a Creative Commons Attribution 4.0 International License, which permits use, sharing, adaptation, distribution and reproduction in any medium or format, as long as you give appropriate credit to the original author(s) and the source, provide a link to the Creative Commons license, and indicate if changes were made. The images or other third party material in this article are included in the article's Creative Commons license, unless indicated otherwise in a credit line to the material. If material is not included in the article's Creative Commons license and your intended use is not permitted by statutory regulation or exceeds the permitted use, you will need to obtain permission directly from the copyright holder. To view a copy of this license, visit http://creativecommons.org/licenses/by/4.0/.

(C) The Author(s) 2019 